\title{
Histopathological Association of Adenomyosis with Various Gynaecological Pathologies
}

\author{
Nishant Sagar, Reena Tomar*, Kirti Balhara, Varuna Mallya, Shramana Mandal and Nita Khurana \\ Dept of Pathology, Maulana Azad Medical College, Delhi, India.
}

\begin{abstract}
Objective: To study the histopathological pattern of endometrium and associated pathological conditions in patients presenting with abnormal uterine bleeding due to adenomyosis.

Material and Methods: The study was conducted at Maulana Azad Medical College, New Delhi and included 87 patients who underwent hysterectomy and were diagnosed with adenomyosis from Jan 2017 to Dec 2019. These cases were subsequently reviewed for presenting symptoms of adenomyosis and correlated with histomorphological features and associated comorbidities. The quantitative variables were expressed as mean and qualitative variables as percentages.

Results and Conclusion: The age of the patients who had adenomyosis ranged from 25 to 65 years, majority were in the age group of 40- 50 years. Abnormal uterine bleeding was the most common symptom. The associated histopathological examination reveals pattern of endometrium from proliferative endometrium to endometrial hyperplasia. Estrogen may be a risk factor as it is associated with fibroid and endometrial hyperplasia.
\end{abstract}

Keywords: Adenomyosis, Abnormal Uterine Bleeding, Endometrium

\section{Introduction}

Adenomyosis is defined as benign invasion of endometrial tissue comprising of both endometrial glands and stroma into the underlying myometrium resulting in diffuse enlargement of the uterus. ${ }^{[1]}$ The adjacent myometrium may show changes related to hyperplasia and/or hypertrophy. ${ }^{[2]}$ The frequency of adenomyosis increases with age of the patient, peaks at 40-50 years of age and then reaches a plateau after menopause. Other risk factors include multiparity, smoking, menstrual irregularities, dilatation and curettage. ${ }^{[3]}$ The prevalence of adenomyosis is highly variable and ranges from $08 \%$ to $20 \%$ in various studies from USA, Germany, Italy, Greece. While studies from Asian subcontinent have reported a prevalence as high as $61.5 \% .^{[4]}$ Wide variation in prevalence may be due to difference in frequency of associated comorbidities in different population that necessitate hysterectomy. [4] Clinical diagnosis of adenomyosis remains largely poor as upto $1 / 3$ to $1 / 2$ of the cases are asymptomatic. Symptomatic patients most commonly present with AUB including menorrhagia, dysmenorrhea, metrorrhagia and rarely dyspareunia. ${ }^{[2,5,6]}$ Adenomyosis is associated with various pathological disorders such as leiomyomata, endometriosis, endometrial polyp, endometrial hyperplasia and carcinoma suggesting an underlying state of hyperestrogenism. ${ }^{[2,7]}$ The diagnosis in majority of patients rests upon histopathological evaluation of hysterectomy specimen since CA-125 levels and radiological procedures are of limited diagnostic utility. ${ }^{[3]}$ The aim of this study is to correlate the presenting symptoms of adenomyosis with histomorphological features and associated comorbidities.

\section{Materials and Methods}

The present study was conducted in Department of Pathology, Maulana Azad Medical College over a period of one and half year. All hysterectomy specimens showing features of adenomyosis on microscopic examination were included in the study and various pathological findings were evaluated. Clinical data was recorded, quantitative parameters were expressed as mean and qualitative parameters as percentage.

\section{Results}

A total of 87 hysterectomy specimens studied had adenomyosis as microscopic findings. The patients ranged from 25 to 75 years with average 43 years of age. Majority of the cases were between 40-50 years,52/87(59.8\%). Abnormal uterine bleeding was the most common symptom seen in 47 patients (54\%) followed by prolapse in 16 cases $(18.4 \%)$. Twenty four patients $(27.6 \%)$ were asymptomatic. The most common endometrial pattern was proliferative endometrium seen in 55 cases. Endometrial hyperplasia was present in 11 cases, secretory phase in 15 cases. Atrophic endometrium was seen in 04 cases, basal endometrium in 02 and hormonal changes were present in one case. Most common coexisting secondary pathology seen in hysterectomy specimens was presence 
of leiyomyomata in 36 cases $(41.4 \%)$ followed by serous cystadenoma in 05 cases $(5.7 \%)$. Endometrial polyp was present in 03 cases. Luteal cyst ovary was present in 05 cases. Endometriosis of ovary and omentum was present in single case. Other less common pathologies encountered were Mucinous cystadenoma ovary, Teratoma, Papillary adenocarcinoma, Serous cystadenocarcinoma, Chronic salpingitis, CIN grade 2 .

\begin{tabular}{|l|l|l|}
\hline $\begin{array}{l}\text { Pattern of endometrium } \\
\text { and associated pathologies }\end{array}$ & $\begin{array}{l}\text { Number } \\
\text { of cases }\end{array}$ & Percentage \\
\hline Proliferative & 55 & 63.2 \\
\hline Secretory & 15 & 17.2 \\
\hline Atrophic & 04 & 4.6 \\
\hline Basal & 02 & 2.3 \\
\hline Hyperplasia & 11 & 12.6 \\
\hline Leiomyomata & 36 & 41.4 \\
\hline Serous cystadenoma & 05 & 5.7 \\
\hline Endometrial polyp & 03 & 3.4 \\
\hline Luteal cyst ovary & 05 & 5.7 \\
\hline $\begin{array}{l}\text { Endometriosis,ovary \& } \\
\text { omentum }\end{array}$ & 01 & 1.1 \\
\hline
\end{tabular}

\section{Discussion}

In 1860, Carl Von Rokitansky described adenomyosis as presence of endometrial glands in the myometrium and coined the pathology as cystosarcoma adenoids uterinum. In 1972, Bird described the condition as benign endometrial glands and stroma present ectopically in the hyperplastic and hypertrophied myometrium, resulting in diffuse enlargement of the uterus. Adenomyosis may be associated with prior history of trauma such as caesarean, dilatation curettage, myomectomy etc. ${ }^{[8,9]}$

Adenomyosis is one of the most common causes of AUB. A classification system developed by FIGO menstrual disorders for AUB known as (PALM-COEIN) stands for Polyps, Adenomyosis, Leiomyomas ,Malignancy and hyperplasia. COEIN stands for Coagulopathy, Ovulatory dysfunction, Endometrial, Iatrogenic and Not yet specified.

Majority of the cases in present study were between the age group of $40-50$ years,52/87(59.8\%). Similar findings were noted in study by Shivananjiah et al and Anwar ali et al with $50 \%$ and $73.7 \%$ cases respectively in $41-50$ years age group. ${ }^{[10,11]}$

Adenomyosis can present with nonspecific symptoms like dysmenorrhea, dyspareunia, chronic pelvic pain, abnormal vaginal bleeding and infertility, while a third of the women are asymptomatic. ${ }^{[8,12]}$ In present study Abnormal uterine bleeding was the most common symptom seen in $47 / 87$ patients (54\%) followed by prolapse in $16 / 87$ cases $(18.4 \%)$ while twenty four patients $(27.6 \%)$ were asymptomatic.

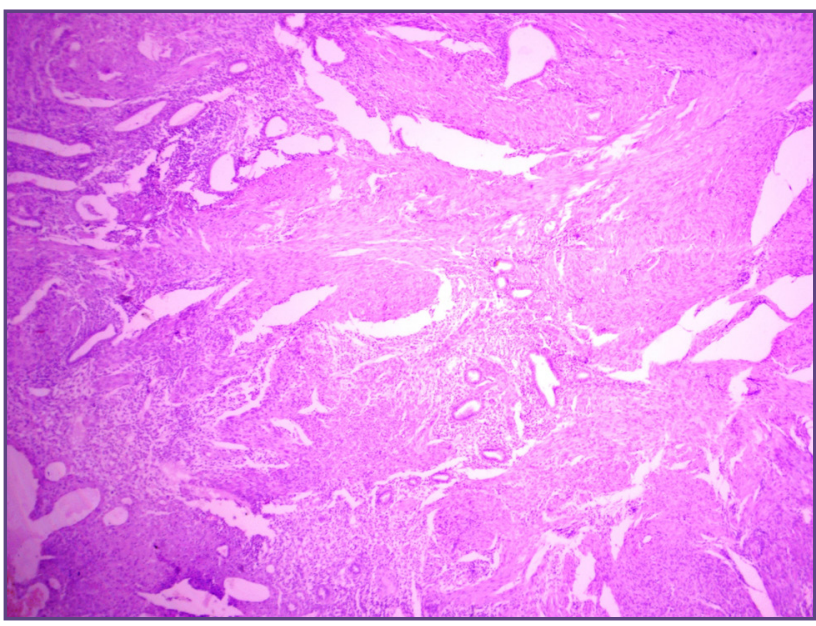

Fig. 1: H\&E 4X showing endometrial gland and stroma infiltrating into the myometrium.

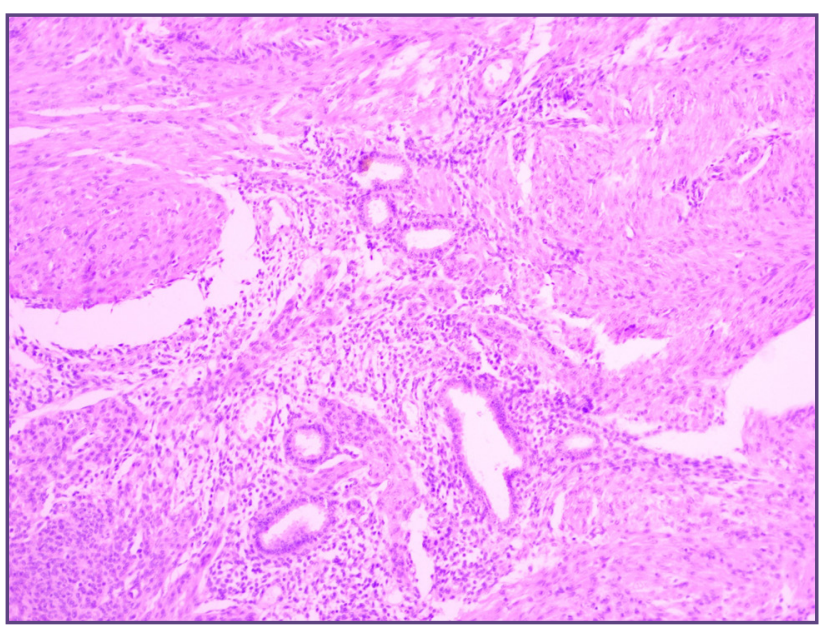

Fig. 2: H\&E 10X showing endometrial gland and stroma infiltrating into the myometrium.

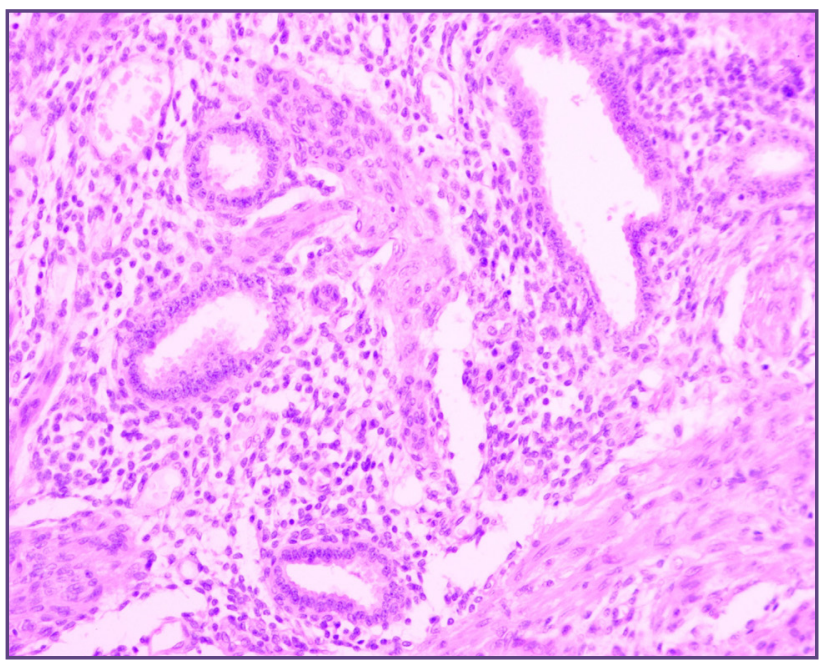

Fig. 3: H\&E 20X showing endometrial gland and stroma. 
In the present study the most common endometrial pattern was proliferative endometrium seen in 55/87 (63.2\%) cases, hyperplasia was present in $11 / 87(12.6 \%)$ cases, secretory phase in $15 / 87(17.2 \%)$ cases, atrophic endometrium was seen in $04 / 87(4.6 \%)$ cases, basal in $02 / 87(2.3 \%)$ and hormonal changes were present in one case(1.1\%). Similar findings were noted by Shivanijiah et al and Dayal et al where proliferative endometrium was seen in $59.1 \%$ and $44.4 \%$ of the cases respectively. ${ }^{[10,13]}$

In present study $36 / 87(41.4 \%$ ) cases had coexisting leiyomyoma while previous studies have reported the existence in $19-57 \%$ cases. ${ }^{[10]}$ Parazzini et al. found significant association between adenomyosis and endometrial hyperplasia. ${ }^{[14]}$ In present study $11 / 87(12.6 \%)$ cases were found to have endometrial hyperplasia. Adenomyosis has been linked to lesions associated with hyperestrogenic state like endometrial polyps and endometrial carcinoma. ${ }^{[15]}$ In present study none of the cases showed endometrial carcinoma while only three cases showed endometrial polyp (3.4\%).

Hysterectomy remains the most important therapeutic option for women with symptomatic adenomyosis who have completed their family. ${ }^{[16,17]}$

\section{Conclusion}

Adenomyosis is a major cause of AUB and contributes largely in decreasing the quality of life index. The associated histopathological findings vary from leiomyoma, endometrial hyperplasia, endometrial polyps and rarely adenocarcinoma. Careful search for gross and microscopic foci of adenomyosis and associated pathologies can help in better management of patients particularly those presenting with abnormal uterine bleeding.

\section{References}

1. Brucker SY, Huebner M, Wallwiener M, Stewart EA, Ebersoll S,Schoenfisch B et al. Clinical characteristics indicating adenomyosis coexisting with leiomyomas: A retrospective questionnaire based study. Fertil Steril 2014;101:237-41.

2. Arunachalam B, Manivasakan J. A clinicopathological study of adenomyosis. J Clin Diagn Res. 2012;6:428-30.

3. Reinhold C, Tafazoli F, Wang L. Imaging features of adenomyosis. Hum Reprod Update. 1998;4:337-49.

4. Bergholt T, Eriksen L, Berendt N, Jacobsen M, Hertz JB. Prevalence and risk factors of adenomyosis at hysterectomy. Hum Reprod. 2001;16:2418-21.
5. Parazzini F, Vercellini P, Panazza S, Chatenoud L, Oldani S, Crosignani PG. Risk factors for adenomyosis. Hum Reprod.1997;12:1275-9.

6. Vavilis D, Agorastos T, Tzafetas J, Loufopoulos A, Vakiani $\mathrm{M}$, Constantinidis $\mathrm{T}$ et al. Adenomyosis at hysterectomy: Prevalence and relationship to operative findings and reproductive and menstrual factors. Clin Exp Obstet Gynecol. 1972;24:36-8.

7. Bird CC, McElin TW, Manalo Estrella P. The elusive adenomyosis of the uterus-revisited. Am J Obstet Gynecol.1972;112:583-93.

8. Sun YL, Wang CB, Lee CY et al. Transvaginal sonographic criteria for the diagnosis of adenomyosis based on histopathologic correlation. Taiwan J Obstet Gynecol. 2010;49(1):40-4.

9. Taran FA, Stewart EA, Brucker S. Adenomyosis: Epidemiology, Risk Factors, Clinical Phenotype and Surgical and Interventional Alternatives to Hysterectomy. Geburtshilfe Frauenheilkd. 2013;73(9):924-31.

10. Shivananjiah C, Nayak A, Swarup A, Honappa S, Swaminathan KR, Pathadan DS. Histopathological pattern of endometrium in Adenomyosis. Indian Journal of Obstetrics and Gynecology Research.2016;3(2):101-3

11. Ali A. The incidence of adenomyosis in hysterectomies. Pak J Med Res.2005;44: 38-40

12. Graziano A, Lo Monte G, Piva I et al. Diagnostic findings in adenomyosis: a pictorial review on the major concerns. Eur Rev Med Pharmac Sci. 2015;19(7):1146-54

13. Dayal S, Nagrath A. Pattern and frequency of endometrial and ovarian pathologies with adenomyosis uteri in patients who attended the tertiary care hospital among rural population of North India. MAC Journal of Medical Sciences. 2015;1(3):147-50

14. Parazzini F, Mais V, Cipriani S, Busacca M, Venturini P. Determinants of adenomyosis in women who underwent hysterectomy for benign gynecological conditions: Results from a prospective multicentric study in Italy. Eur J Obstet Gynecol Reprod Biol. 2009;143:103- 6.

15. Verit FF, Yucel O. Endometriosis, Leiomyoma and Adenomyosis: the risk of gynecologic malignancy. Asian Pac J Cancer Prev. 2013;14(10):5589-97.

16. Horng $\mathrm{HC}$, Chen $\mathrm{CH}$, Chen $\mathrm{CY}$ et al. Uterine-sparing surgery for adenomyosis and/or adenomyoma. Taiwan $\mathrm{J}$ Obstet Gynecol. 2014;53(1):3-7.

17. Shu S, Luo X, Wang Z et al. Fifteen cases clinical analysis of wedge-shaped resection of uterus treating adenomyosis CONSORT. Medicine. 2016;95(24):e3805.

*Corresponding author:

Dr. Reena Tomar, Room No 258, Dept Of Pathology, Maulana Azad Medical College, New Delhi, India

Phone: +91 9968604481

Email: drreenat@yahoo.com

Financial or other Competing Interests: None. 